\title{
Assessing the correlation between FDG PET findings of IDC breast carcinoma and histopathology of coexisting ductal carcinoma in-situ
}

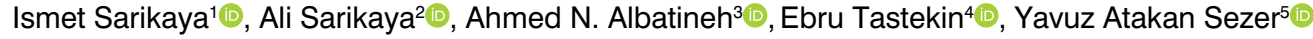 \\ ${ }^{1}$ Faculty of Medicine, Department of Nuclear Medicine, Kuwait University, Kuwait \\ 'Faculty of Medicine, Department of Nuclear Medicine, Trakya University, Edirne, Turkey \\ ${ }^{3}$ Faculty of Medicine, Department of Community Medicine and Behavioral Sciences, Kuwait University, Kuwait \\ ${ }^{4}$ Faculty of Medicine, Department of Pathology, Trakya University, Edirne, Turkey \\ ${ }^{5}$ Faculty of Medicine, Department of Surgery, Trakya University, Edirne, Turkey
}

[Received 2 XI 2020; Accepted 15 III 2021]

\begin{abstract}
Background: Ductal carcinoma in-situ (DCIS) often coexists with invasive ductal carcinoma (IDC) of the breast. DCIS is considered as a non-obligate precursor of IDC when both coexist. ${ }^{18} \mathrm{~F}$-fluorodeoxyglucose positron emission tomography/computed tomography $\left(\left[{ }^{18} \mathrm{~F}\right] \mathrm{FDG} \mathrm{PET} / \mathrm{CT}\right)$ imaging is commonly used in the staging and follow-up assessment of breast cancer. In this study, we aimed to assess if there is any correlation between primary tumor PET and histopathology findings and histopathological features of the coexisting DCIS.
\end{abstract}

Material and methods: FDG PET/CT images and histopathology results of the patients with newly diagnosed breast cancer (IDC) with coexisting DCIS were analyzed in this retrospective study. The grade and size of the primary tumor and histopathological features of the coexisting DCIS (nuclear grade and architectural pattern) were obtained from the postoperative histopathology results. Maximum standardized uptake values (SUV: SUV ${ }_{\max }$ and $\mathrm{SUL}_{\max }$ ) of the primary tumor normalized by weight and lean body mass were measured. Statistical analysis was performed to assess the correlation between various parameters of IDC and DCIS.

Results: This study included sixty-two (62) patients with IDC-DCIS. Primary tumor grade was significantly correlated and associated with the nuclear grade of the coexisting DCIS (polychoric correlation $r=0.736$, and Fisher exact test, PV $<0.001$, respectively). Primary tumor SUV was not correlated with the nuclear grade and architectural pattern of the coexisting DCIS (polyserial correlation $r=0.172, \mathrm{PV}=0.155$, and Point Bi-Serial correlation $r=-0.009, \mathrm{PV}=0.955$, respectively). Median primary tumor size was marginally significantly different among DCIS nuclear grades but it was not significantly different in comedo and non-comedo cases (Kruskal-Wallis test PV $=0.053$, and Mann-Whitney U test PV $=0.890$, respectively).

Conclusions: Primary tumor grade is correlated with the nuclear grade of the coexisting DCIS. SUV of primary tumor does not seem to be correlated with the histopathological features of coexisting DCIS (nuclear grade and architectural pattern) but this may be further studied in a larger number of patients.

KEY words: breast carcinoma; invasive ductal carcinoma; coexisting DCIS; FDG PET; nuclear grade; architectural pattern Nucl Med Rev 2022; 25, 1: 6-11

Correspondence to: Ismet Sarikaya

Department of Nuclear Medicine, Faculty of Medicine,

Kuwait University, PO Box 24923

Safat, Kuwait 13110, tel.: (965) 25319592/6414, fax: (965) 25338936

e-mail: isarikaya99@yahoo.com

This article is available in open access under Creative Common Attribution-Non-Commercial-No Derivatives 4.0 International (CC BY-NC-ND 4.0) license, allowing to download articles and share them with others as long as they credit the authors and the publisher, but without permission to change them in any way or use them commercially. 


\section{Introduction}

Ductal carcinoma in situ (DCIS) is a pre-invasive (non-invasive) type of breast cancer. In DCIS, malignant ductal epithelial cell proliferations remain confined within the intact breast ducts [1]. DCIS often coexists with invasive ductal carcinoma (IDC) of the breast $[2,3]$. DCIS is recognized as the non-obligate precursor of IDC when both of them coexist $[4,5]$. In tumors with no coexisting DCIS (pure IDC), it is assumed that IDC arises de novo $[6,7]$.

${ }^{18} \mathrm{~F}$-fluorodeoxyglucose ( $\left.\left[{ }^{18} \mathrm{~F}\right] \mathrm{FDG}\right)$ positron emission tomography/computed tomography (PET/CT) is widely used for initial staging/detecting distant metastases of high-risk locally advanced invasive and inflammatory breast cancers, particularly where standard staging studies show equivocal or suspicious results [8-10]. FDG uptake is usually higher in IDC and inflammatory breast cancer and lower in invasive lobular carcinoma of the breast $[8,11]$. DCIS lesions usually show a low degree of FDG uptake [12]. FDG uptake (metabolic activity of the tumor) is positively correlated with the tumor grade and proliferation (Ki-67 expression) and negatively correlated with the hormonal receptor status of breast cancer $[8,13]$. Estrogen and progesterone receptor (ER and PR) negative tumors demonstrate higher metabolic activity than receptor-positive tumors [11, 14]. Triple-negative breast cancer (negative for ER, $\mathrm{PR}$, and HER2) usually shows high FDG uptake (high metabolic activity) and is associated with poor prognosis [14, 15].

In a recently published study, we have compared FDG PET/CT findings of IDC-DCIS and pure IDC cases [16]. In the current study, our aim was to assess if there is any correlation between primary tumor's (IDC) PET and histopathology findings and histopathological features of the coexisting DCIS. We wanted to understand if FDG PET findings can support the hypothesis of DCIS as the precursor of IDC when they coexist.

\section{Material and methods}

Histopathology results of the newly diagnosed breast cancer patients who had FDG PET/CT imaging for initial staging and prior to any treatment were reviewed. Patients with IDC and coexisting DCIS (IDC-DCIS) were selected for further analysis.

This retrospective study was approved by two institutes (Kuwait Ministry of Health and Trakya University Faculty of Medicine Health and Ethics Committee).

FDG PET/CT images were obtained approximately $60 \mathrm{~min}$ following intravenous injection of 222-296 MBq (6-8 mCi) of $\left[{ }^{18} \mathrm{~F}\right] \mathrm{FDG}$ using Philips Gemini Time of Flight (Philips Medical Systems, Best, Netherlands) and GE discovery 8 (General Electric Medical Systems, Milwaukee, WI, USA) PET/CT cameras. First, a low-dose CT was obtained (for attenuation correction and anatomic localization). PET image acquisition was 2-3 min/bed from vertex to mid-thigh levels. PET images were corrected for attenuation using the CT data. PET images were reconstructed using a standard iterative algorithm and reformatted into transaxial, coronal, and sagittal planes. A maximum intensity projection image was generated.

FDG PET/CT images were evaluated by 2 board-certified Nuclear Medicine physicians with over 30 years of experience. Weight and lean body mass normalized maximum standardized uptake values $\left(S \mathrm{SV}_{\max }\right.$ and SUL $\mathrm{Lax}_{\max }$ ) of the primary tumors were measured. $\mathrm{PET} / \mathrm{CT}$ images were reviewed to assess the primary tumor, regional and distant metastases, and additional findings but those were not included in the analysis.

Histopathology results were reviewed to collect information for the features of the primary tumor (grade and size) and coexisting DCIS (nuclear grade and architectural subtype).

\section{Statistical analysis}

The statistical analysis was conducted using the SPSS statistical software (Version 24) and R statistical software. Counts and percentages were reported for categorical variables and means (SD) were reported for continuous variables. Two sample t-test or Mann-Whitney $U$ tests were used to compare two continuous variables depending on the data normality condition. Analysis of variance (ANOVA) or Kruska-Wallis test was used to compare a continuous outcome and a three or more levels categorical covariate. The strength of the associations was measured by correlation coefficients of either Spearman rank correlation, point biserial correlation, polyserial correlation, or polychoric correlations depending on the type of variables under investigation. All tests were two-tailed, and $\mathrm{p}$-values $<0.05$ were considered statistically significant.

\section{Results}

Sixty-two (62) female patients with newly diagnosed IDC-DCIS from 2 institutes (Mubarak Al-Kabeer hospital: 26 patients and Trakya University hospital: 36 patients) were included in this study (mean age $55.2 \pm 9.5$ years).

Patients underwent various surgeries such as mastectomy, wide local excision, or breast preservation surgery (lumpectomy or segmental mastectomy). All of the patients also had sentinel lymph node biopsy and/or axillary dissection. Some of the patients received neoadjuvant chemotherapy before the surgery (after PET imaging). TNM staging of the tumors is available in our data but not provided in this article.

Primary tumor grade was grade- 3 in 28 patients, grade- 2 in 27 , and grade- 1 in 7 patients. The nuclear grade of the coexisting DCIS was grade- 3 in 38 patients, grade- 2 in 13 , and grade- 1 in 8 patients. Nuclear grade of the DCIS in 3 patients and the size of the primary tumor in 5 patients were not available in the pathology report. The architectural pattern of the coexisting DCIS was mainly mixed (combination of at least 2 of the following patterns; solid, papillary, micropapillary, cribriform, and comedo, 49 patients) andthe rest of the patients showed only solid pattern (13 patients). For statistical comparison, we further classified the architectural pattern as comedo (37 patients) and non-comedo (25 patients) based on the presence of comedo necrosis. Figure 1 and 2 shows primary tumor grade versus a nuclear grade of coexisting DCIS and nuclear grade versus architectural subtype of DCIS, respectively.

\section{Statistical results}

Primary tumor SUVS (SUV ${ }_{\text {max }}$ and $S U L_{\text {max }}$ ) were not significantly correlated with the nuclear grade of the coexisting DCIS (Polyserial correlation, $r=0.172 ; P V=0.155$ and $r=0.158$, and $P V=0.211$, respectively). Median primary tumor SUVS (SUV ${ }_{\max }$ and $S U L_{\max }$ ) were higher in nuclear grade-3 than nuclear grade-2 and -1 cases but according to the Kruskal-Wallis test, they were 


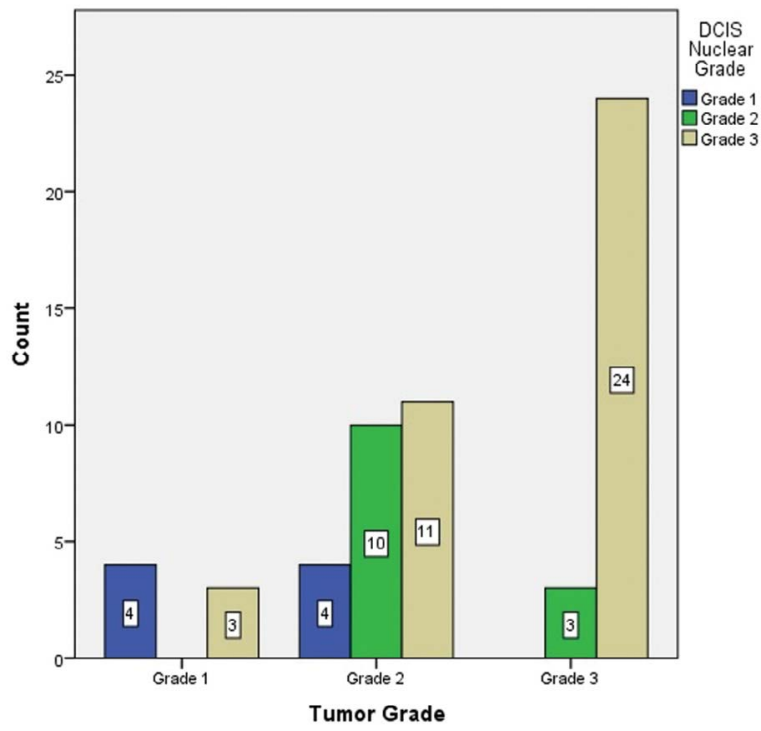

Figure 1. Primary tumor grade versus nuclear grade of the coexisting DCIS; count - number of patients)

not significantly different ( $P V=0.288$, and 0.340 , respectively) (Fig. 3, Tab. 1).

Primary tumor SUVS (SUV $\max _{\text {ax }}$ and $S \mathrm{SL}_{\max }$ ) were not correlated with the architectural pattern of the coexisting DCIS (Point Bi-Serial correlation, $r=-0.009$, $\mathrm{PV}=0.955$ and $r=-0.017, \mathrm{PV}=0.919$, respectively). Median primary tumor SUVs (SUV ${ }_{\text {max }}$ and $S U L_{\text {max }}$ ) were higher in comedo than non-comedo coexisting DCIS, but according to the Mann-Whitney $U$ test, they were not significantly different ( $P V=0.966$, and 0.886, respectively) (Fig. 3, Tab. 2).

Primary tumor grade was correlated with the nuclear grade (Polychoric correlation, $r=0.736, \mathrm{PV}<0.001$ ) but not with the architectural pattern (Polychoric correlation, $r=0.265, \mathrm{PV}=0.157$ )

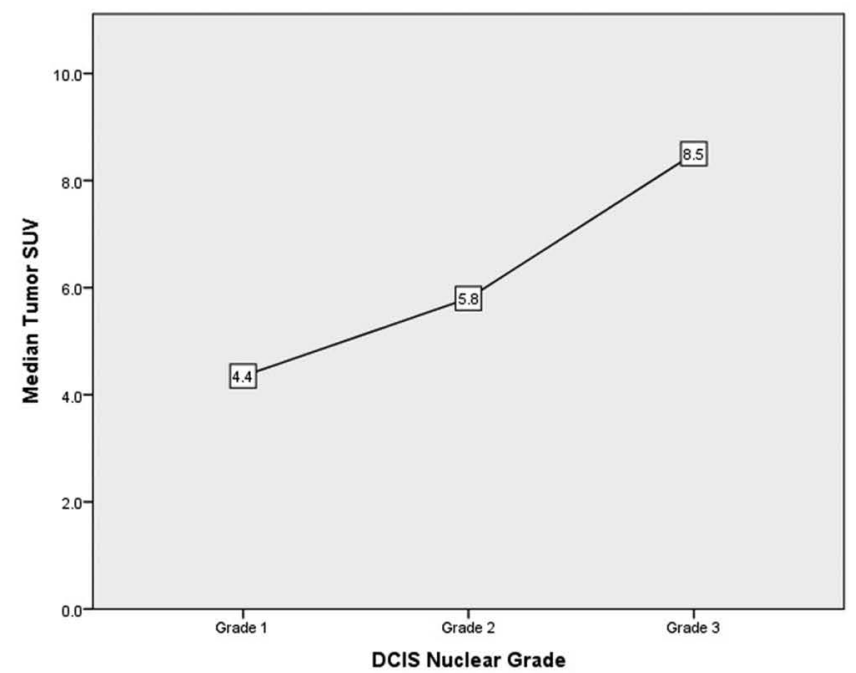

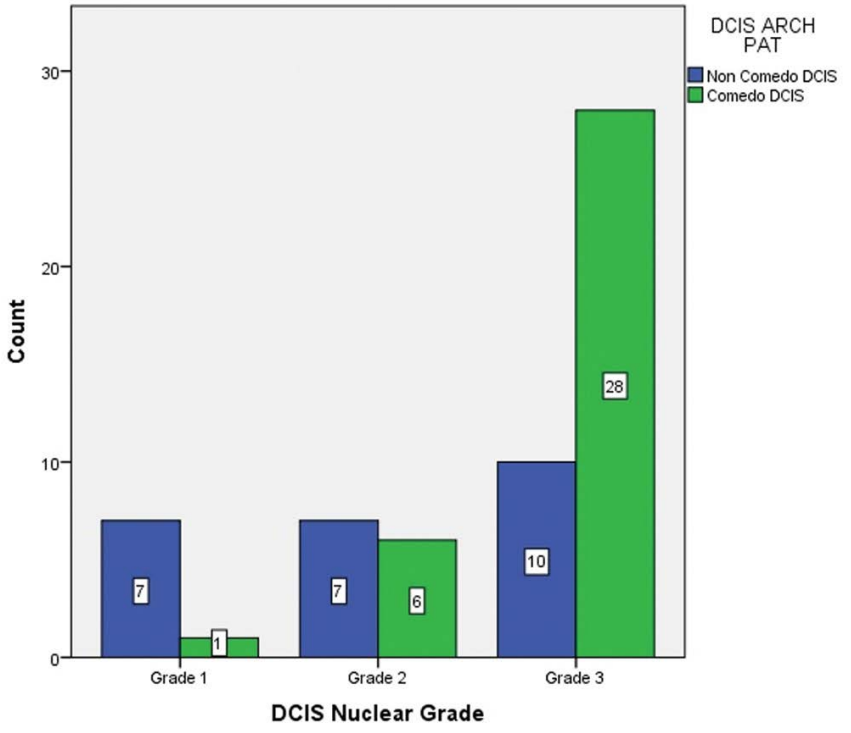

Figure 2. Nuclear grade versus the architectural pattern of coexisting ductal carcinoma in-situ (DCIS); Count — number of patients)

of the coexisting DCIS. There was a significant association between the primary tumor grade and nuclear grade of the coexisting DCIS (Fisher exact test, $\mathrm{PV}<0.001$ ), but no significant association between primary tumor grade and architectural pattern of the coexisting DCIS (comedo versus non-comedo) (Fisher exact test, $\mathrm{PV}=0.233$ )

According to the Kruskal-Wallis test, there was marginally significant evidence that the median primary tumor size among DCIS nuclear grade was different $(P V=0.053)$ but according to the Mann-Whitney $U$ test, the median primary tumor size in comedo and non-comedo cases were not significantly different $(P V=0.890)$ (Tab. 1 and 2, Fig. 4).

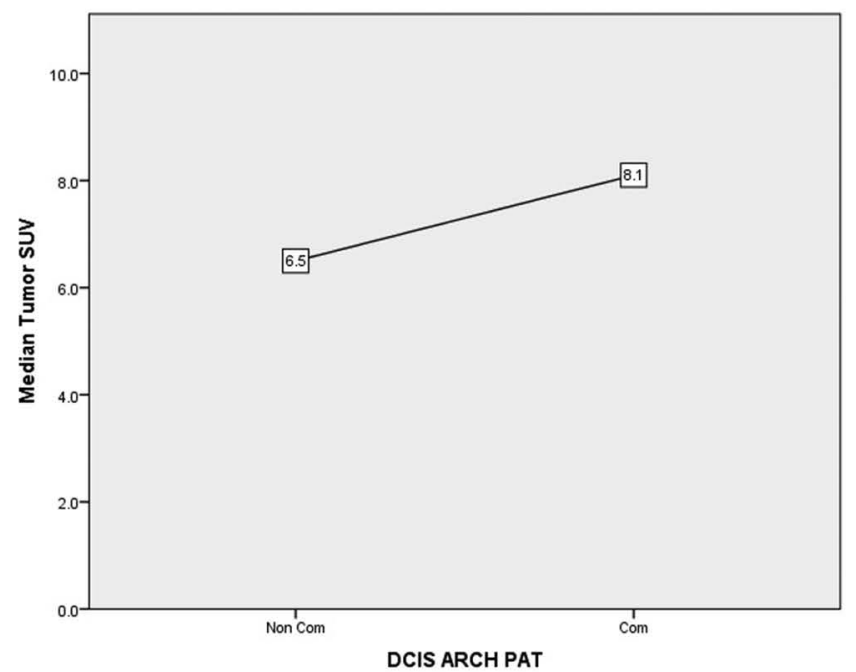

Figure 3. Graphs of median primary tumor SUV versus nuclear grade and architectural pattern (comedo and non-comedo) of coexisting ductal carcinoma in-situ (DCIS). Median SUVs are shown in boxes 
Table 1. Tests of differences in primary tumor (IDC) size, primary tumor $\mathrm{SUV}_{\max }$, and primary tumor $\mathrm{SUL}_{\max }$ according to primary tumor grade and nuclear grade of coexisting ductal carcinoma in-situ (DCIS)

\begin{tabular}{|c|c|c|c|c|c|c|}
\hline Covariate & $\begin{array}{c}\text { Primary Tumor Size }(\mathrm{cm}) \\
\text { median }\end{array}$ & $\mathrm{p}$-value & $\begin{array}{l}\text { Primary Tumor SUV } \\
\text { median }\end{array}$ & $p$-value & $\begin{array}{l}\text { Primary Tumor SUL }{ }_{\text {max }} \\
\text { (n)(median) }\end{array}$ & $\mathrm{p}$-value \\
\hline Primary Tumor Grade & & $0.001^{\dagger}$ & & $0.013^{\dagger}$ & & $0.010^{\dagger}$ \\
\hline Grade 1 & 1.05 & & 3.8 & & 2.75 & \\
\hline Grade 2 & 2.40 & & 6.25 & & 3.40 & \\
\hline Grade 3 & 3.10 & & 8.70 & & 5.60 & \\
\hline $\begin{array}{l}\text { Nuclear Grade of } \\
\text { Coexisting DCIS }\end{array}$ & & $0.053^{\dagger}$ & & $0.288^{\dagger}$ & & $0.340^{+}$ \\
\hline Grade 1 & 1.6 & & 4.35 & & 2.70 & \\
\hline Grade 2 & 3.15 & & 5.75 & & 3.40 & \\
\hline Grade 3 & 2.75 & & 8.5 & & 4.70 & \\
\hline
\end{tabular}

${ }^{\dagger} p$-value calculated using Kruskal-Wallis test
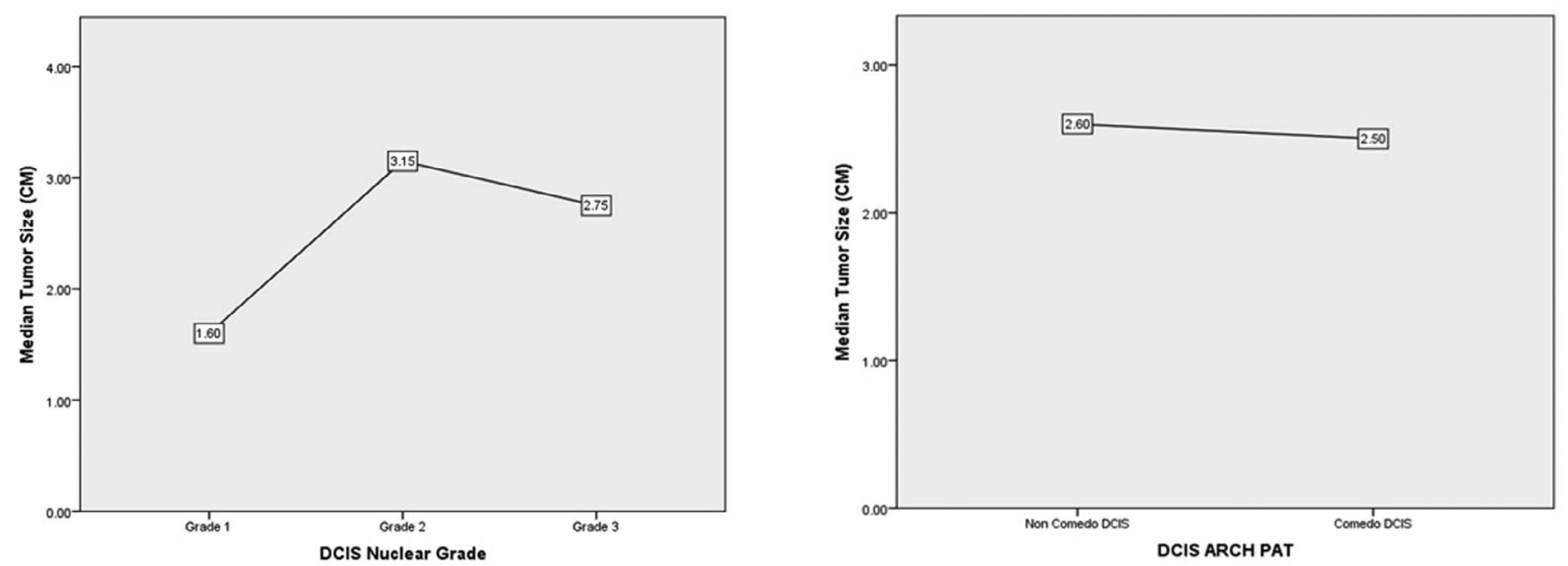

Figure 4. Graphs of median primary tumor size versus nuclear grade and architectural pattern (comedo and non-comedo) of coexisting ductal carcinoma in-situ (DCIS). Median sizes are shown in boxes

As expected, primary tumor grade was significantly correlated with the primary tumor SUVs (SUV max $_{\text {and }}$ SUL ${ }_{\max }$ ) (Polyserial correlation, $r=0.312$, PV 0.023, and $r=0.303, P V=0.024$, respectively). According to the Kruskal-Wallis test, there was evidence of a significant difference in median primary tumor SUVs (SUV ${ }_{\text {max }}$ and SUL ${ }_{\text {max }}$ ) across primary tumor grades ( $P V=0.013$, and 0.010 , respectively) (Tab. 1). Primary tumor grade was significantly correlated with the primary tumor size (Polyserial correlation, $r=0.545$, PV $<0.001$ ) (Tab. 1). Also, the nuclear grade of the DCIS was significantly correlated with the architectural pattern of the DCIS (Polychoric correlation, $r=0.614, \mathrm{PV}<0.001)$.

\section{Discussion}

DCIS often coexists with IDC (32\% and $63.1 \%$ of the cases) [2, 3]. DCIS is recognized as the non-obligate precursor of IDC when they coexist $[4,5]$. It was suggested that up to $50 \%$ of patients with microscopic foci of DCIS develop invasive carcinomas of the breast [4]. The invasive lesion occurs in the same region as the original DCIS lesion which indicates a precursor process $[4,17]$. Other studies have also supported the hypothesis of transition from DCIS to IDC based on the concordant expression of immunohistochemical markers, biomarkers, and genomic data [18-26]. Progression from DCIS to invasive breast cancer may follow a Darwinian evolutionary model [5].

Histologic parameters of the clinical significance of DCIS include architectural subtypes/patterns, nuclear grade, size and extent of the lesion, status of microcalcifications, necrosis, and margins [27]. The nuclear grade of the DCIS lesions is classified as low grade (grade-1), intermediate grade (grade-2), and high grade (grade-3). Grade-3 DCIS is composed of pleomorphic large cells and abundant mitoses. High nuclear grade DCIS is an aggressive subtype of DCIS with an overall poorer prognosis as compared to low and intermediate nuclear grade DCIS [28]. DCIS with low-nuclear grade 
Table 2. Testing median differences of primary tumor size, primary tumor SUV ${ }_{\max }$, and primary tumor SUL ${ }_{\max }$ by architectural subtype of coexisting ductal carcinoma in-situ (DCIS)

\begin{tabular}{lccc}
\hline Covariate & $\begin{array}{c}\text { Architectural Subtype of Coexisting DCIS } \\
\text { Comedo }\end{array}$ & $\begin{array}{l}\text { p-value }{ }^{\dagger} \\
\text { Non-Comedo }\end{array}$ \\
$\begin{array}{l}\text { Primary Tumor Size } \\
\text { (cm, median) }\end{array}$ & 2.50 & 2.60 & 0.890 \\
$\begin{array}{l}\text { Primary Tumor SUV } \\
\text { (max }\end{array}$ & 8.1 & 6.5 & 0.966 \\
$\begin{array}{l}\text { Primary Tumor SUL } \\
\text { (median) }\end{array}$ & 4.50 & 3.70 & 0.886 \\
${ }^{\dagger} \mathrm{p}$-value was obtained according to Mann-Whitney U test &
\end{tabular}

composed of uniform cells with small size and low-mitotic rate. In intermediate nuclear grade DCIS, neoplastic nuclei show pleomorphism (between high- and low- nuclear grade DCIS).

The architectural patterns of DCIS are classified as solid, comedo necrosis (comedo), cribriform, micropapillary, and papillary. DCIS commonly demonstrates a mixed pattern. DCIS is usually categorized as comedo and non-comedo. The comedo subtype of DCIS is defined by high-grade cells, prominent necrosis in the center of the ducts, and a high proliferation rate [29, 30]. Non-comedo subtypes of DCIS are composed of low-grade cells, and a low proliferation rate [27]. Angiogenesis and foci of microinvasion are common around comedo lesions and low in non-comedo lesions [31-33]. Ketcham et al. have indicated there is more often and more rapid progression into invasive carcinoma from highgrade DCIS as compared to low-grade [34].

In the current study, there was a significant correlation and association between the grade of the primary tumor and the nuclear grade of the coexisting DCIS. Median primary tumor SUV was higher in nuclear grade- 3 cases and comedo pattern as compared to cases with nuclear grade- 1 and- 2 and non-comedo pattern but it was not statistically significant. This result may be affected by the relatively small number of nuclear grade- $1(n=8)$ and $-2(n=12)$ cases in our study. In a recently published study, we did not find a significant difference in primary tumor SUV in IDC-DCIS and pure IDC cases but multifocal tumor and multifocal uptake were more common in IDC-DCIS cases [16]. As expected, in the current study primary tumor grade was significantly correlated with the primary tumor's metabolic activity and nuclear grade of the DCIS was significantly correlated with the architectural pattern of the DCIS $[8,13,29,30]$.

Studies have also reported that IDC-DCIS show lower metastatic potential and recurrence and better overall survival as compared to pure IDC but some other studies show controversial results [6, $7,23,35,36]$. In our recent study, axillary metastases appeared to be more common in pure IDC than IDC-DCIS cases [16].

A limitation of this study could be the relatively small number of patients, particularly patients with nuclear grade- 1 and -2 coexisting DCIS. Assessing primary tumor metabolic activity alone is not adequate to understand if DCIS could be the precursor of IDC in IDC-DCIS cases but it may be supportive if primary tumor SUV correlates with the nuclear grade of coexisting DCIS. This preliminary study also serves as the only available data in the literature investigating the correlation between PET findings of the primary tumor (IDC) with the histopathological findings of the coexisting DCIS.

\section{Conclusions}

Primary tumor grade is significantly correlated with the nuclear grade of the coexisting DCIS. SUV of primary tumor does not seem to be significantly correlated with the histopathological features of the coexisting DCIS (nuclear grade and architectural pattern) but this may be studied in a larger number of patients.

\section{Conflict of interest}

There is no potential conflict of interest relevant to this article.

\section{Acknowledgments}

Dr. Ahmed N. Albatineh and Dr. Ebru Tastekin contributed to the manuscript equally both as $3^{\text {rd }}$ authors.

\section{References}

1. Barnes NLP, Ooi JL, Yarnold JR, et al. Ductal carcinoma in situ of the breast. BMJ. 2012; 344: e797, doi: 10.1136/bmj.e797, indexed in Pubmed: 22378935

2. Jo BH, Chun YK. Heterogeneity of invasive ductal carcinoma: proposal for a hypothetical classification. J Korean Med Sci. 2006; 21(3): 460-468, doi: 10.3346/jkms.2006.21.3.460, indexed in Pubmed: 16778390.

3. Logullo AF, Godoy AB, Mourão-Neto M, et al. Presence of ductal carcinoma in situ confers an improved prognosis for patients with T1NOMO invasive breast carcinoma. Braz J Med Biol Res. 2002; 35(8): 913-919, doi: 10.1590/s0100-879x2002000800008, indexed in Pubmed: 12185383.

4. Pinder SE, Ellis $I O$. The diagnosis and management of pre-invasive breast disease: ductal carcinoma in situ (DCIS) and atypical ductal hyperplasia (ADH)--current definitions and classification. Breast Cancer Res. 2003; 5(5): 254-257, doi: 10.1186/bcr623, indexed in Pubmed: 12927035.

5. Cowell CF, Weigelt B, Sakr RA, et al. Progression from ductal carcinoma in situ to invasive breast cancer: revisited. Mol Oncol. 2013; 7(5): 859-869, doi: 10.1016/j.molonc.2013.07.005, indexed in Pubmed: 23890733.

6. Dieterich M, Hartwig F, Stubert J, et al. Accompanying DCIS in breast cancer patients with invasive ductal carcinoma is predictive of improved local recurrence-free survival. Breast. 2014; 23(4): 346-351, doi: 10.1016/j. breast.2014.01.015, indexed in Pubmed: 24559611.

7. Wong H, Lau S, Yau T, et al. Presence of an in situ component is associated with reduced biological aggressiveness of size-matched invasive breast cancer. Br J Cancer. 2010; 102(9): 1391-1396, doi: 10.1038/sj.bjc.6605655, indexed in Pubmed: 20424617.

8. Groheux D, Cochet A, Humbert O, et al. ${ }^{1}$ F-FDG PET/CT for Staging and Restaging of Breast Cancer. J Nucl Med. 2016; 57 Suppl 1: 17S-26S, doi: 10.2967/jnumed.115.157859, indexed in Pubmed: 26834096.

9. Edge SB, Compton CC. The American Joint Committee on Cancer: the 7th edition of the AJCC cancer staging manual and the future of TNM. Ann Surg Oncol. 2010; 17(6): 1471-1474, doi: 10.1245/s10434-010-0985-4, indexed in Pubmed: 20180029.

10. NCCN Clinical Practice Guidelines in Oncology (NCCN Guidelines). National Comprehensive Cancer Network. Version 4.2017-February 7, 2018.

11. Groheux D, Giacchetti S, Moretti JL, et al. Correlation of high 18F-FDG uptake to clinical, pathological and biological prognostic factors in breast cancer. Eur J Nucl Med Mol Imaging. 2011; 38(3): 426-435, doi: 10.1007/s00259-010-1640-9, indexed in Pubmed: 21057787. 
12. Avril N, Menzel M, Dose J, et al. Glucose metabolism of breast cancer assessed by 18F-FDG PET: histologic and immunohistochemical tissue analysis. J Nucl Med. 2001; 42(1): 9-16, indexed in Pubmed: 11197987.

13. Gil-Rendo A, Martínez-Regueira F, Zornoza G, et al. Association between [18F]fluorodeoxyglucose uptake and prognostic parameters in breast cancer. Br J Surg. 2009; 96(2): 166-170, doi: 10.1002/bjs.6459, indexed in Pubmed: 19160365

14. Yoon HJ, Kang KW, Chun InK, et al. Correlation of breast cancer subtypes, based on estrogen receptor, progesterone receptor, and HER2, with functional imaging parameters from Ga-RGD PET/CT and ${ }^{1}$ F-FDG PET/CT. Eur J Nucl Med Mol Imaging. 2014; 41(8): 1534-1543, doi: 10.1007/s00259014-2744-4, indexed in Pubmed: 24652232.

15. Gonçalves H, Guerra MR, Duarte Cintra JR, et al. Survival Study of Triple-Negative and Non-Triple-Negative Breast Cancer in a Brazilian Cohort. Clin Med Insights Oncol. 2018; 12: 1179554918790563, doi: 10.1177/1179554918790563, indexed in Pubmed: 30083066.

16. Sarikaya I, Sarikaya A, Albatineh AN, et al. Is there a difference in FDG PET findings of invasive ductal carcinoma of the breast with and without coexisting DCIS? Asia Ocean J Nucl Med Biol. 2020; 8: 27-35.

17. Betsill WL, Rosen PP, Lieberman $\mathrm{PH}$, et al. Intraductal carcinoma. Long-term follow-up after treatment by biopsy alone. JAMA. 1978; 239(18): 1863-1867, doi: 10.1001/jama.239.18.1863, indexed in Pubmed: 205686.

18. Steinman S, Wang J, Bourne P, et al. Expression of cytokeratin markers, ER-alpha, PR, HER-2/neu, and EGFR in pure ductal carcinoma in situ (DCIS) and DCIS with co-existing invasive ductal carcinoma (IDC) of the breast. Ann Clin Lab Sci. 2007; 37(2): 127-134, indexed in Pubmed: 17522367.

19. Alexe G, Dalgin GS, Ganesan S, et al. Analysis of breast cancer progression using principal component analysis and clustering. J Biosci. 2007; 32(5): 1027-1039, doi: 10.1007/s12038-007-0102-4, indexed in Pubmed: 17914245

20. Aubele $\mathrm{M}$, Mattis $\mathrm{A}$, Zitzelsberger $\mathrm{H}$, et al. Extensive ductal carcinoma In situ with small foci of invasive ductal carcinoma: evidence of genetic resemblance by CGH. Int J Cancer. 2000; 85(1): 82-86, doi: 10.1002/ (sici)1097-0215(20000101)85:1<82::aid-ijc15>3.0.co;2-s, indexed in Pubmed: 10585588.

21. lakovlev VV, Arneson NCR, Wong V, et al. Genomic differences between pure ductal carcinoma in situ of the breast and that associated with invasive disease: a calibrated aCGH study. Clin Cancer Res. 2008; 14(14): 4446-4454, doi: 10.1158/1078-0432.CCR-07-4960, indexed in Pubmed: 18628458

22. Castro NP, Osório CA, Torres C, et al. Evidence that molecular changes in cells occur before morphological alterations during the progression of breast ductal carcinoma. Breast Cancer Res. 2008; 10(5): R87, doi: 10.1186/bcr2157, indexed in Pubmed: 18928525.

23. Schuetz CS, Bonin M, Clare SE, et al. Progression-specific genes identified by expression profiling of matched ductal carcinomas in situ and invasive breast tumors, combining laser capture microdissection and oligonucleotide microarray analysis. Cancer Res. 2006; 66(10): 5278-5286, doi: 10.1158/0008-5472.CAN-05-4610, indexed in Pubmed: 16707453
24. Wong $\mathrm{H}$, Lau $\mathrm{S}$, Leung $\mathrm{R}$, et al. Coexisting ductal carcinoma in situ independently predicts lower tumor aggressiveness in node-positive luminal breast cancer. Med Oncol. 2012; 29(3): 1536-1542, doi: 10.1007/s12032011-0082-y, indexed in Pubmed: 21983862.

25. Buerger $\mathrm{H}$, Otterbach $\mathrm{F}$, Simon R, et al. Comparative genomic hybridization of ductal carcinoma in situ of the breast-evidence of multiple genetic pathways. J Pathol. 1999; 187(4): 396-402, doi: 10.1002/(SICI)10969896(199903)187:4<396::AID-PATH286>3.0.CO;2-L, indexed in Pubmed: 10398097

26. Burkhardt L, Grob TJ, Hermann I, et al. Gene amplification in ductal carcinoma in situ of the breast. Breast Cancer Res Treat. 2010; 123(3): 757-765, doi: 10.1007/s10549-009-0675-8, indexed in Pubmed: 20033484.

27. Siziopikou KP. Ductal carcinoma in situ of the breast: current concepts and future directions. Arch Pathol Lab Med. 2013; 137(4): 462-466, doi: 10.5858/arpa.2012-0078-RA, indexed in Pubmed: 23544935.

28. Ballard LJ, Ballard GV. High-grade ductal carcinoma in situ: An overview for the radiologist. J Am Osteopath Coll Rad. 2013; 2: 18-25.

29. Fitzgibbons PL, Henson DE, Hutter RV. Benign breast changes and the risk for subsequent breast cancer: an update of the 1985 consensus statement. Cancer Committee of the College of American Pathologists. Arch Pathol Lab Med. 1998; 122(12): 1053-1055, indexed in Pubmed: 9870852.

30. Consensus Conference on the classification of ductal carcinoma in situ. The Consensus Conference Committee. Cancer. 1997; 80(9): 1798-1802, doi: 10.1002/(sici)1097-0142(19971101)80:9<1798::aid-cncr15>3.0.co;2-0, indexed in Pubmed: 9351550.

31. Guidi AJ, Schnitt SJ, Fischer L, et al. Microvessel density and distribution in ductal carcinoma in situ of the breast. J Natl Cancer Inst. 1994; 86(8): 614-619, doi: 10.1093/jnci/86.8.614, indexed in Pubmed: 7511693.

32. Engels K, Fox SB, Whitehouse RM, et al. Distinct angiogenic patterns are associated with high-grade in situ ductal carcinomas of the breast. J Pathol. 1997; 181(2): 207-212, doi: 10.1002/(SICI)1096-9896(199702)181:2<207::AIDPATH758 > 3.0.CO;2-4, indexed in Pubmed: 9120727.

33. Lagios M, Westdahl P, Margolin F, et al. Duct carcinomain situ. Relationship of extent of noninvasive disease to the frequency of occult invasion, multicentricity, lymph node metastases, and short-term treatment failures. Cancer. 1982; 50(7): 1309-1314, doi: 10.1002/1097-0142(19821001)50:7<1309::aid-cncr2820500716>3.0.co;2-\#

34. Ketcham A, Moffat F. Vexed surgeons, perplexed patients, and breast cancers which may not be cancer. Cancer. 1990; 65(3): 387-393, doi: 10.1002/1097-0142(19900201)65:3<387::aid-cncr2820650302>3.0.co;2-y.

35. Chagpar AB, McMasters KM, Sahoo S, et al. Does ductal carcinoma in situ accompanying invasive carcinoma affect prognosis? Surgery. 2009; 146(4): 561-7; discussion 567, doi: 10.1016/j.surg.2009.06.039, indexed in Pubmed: 19789013

36. Mylonas I, Makovitzky J, Jeschke U, et al. Expression of Her2/neu, steroid receptors (ER and PR), Ki67 and p53 in invasive mammary ductal carcinoma associated with ductal carcinoma In Situ (DCIS) Versus invasive breast cancer alone. Anticancer Res. 2005; 25(3A): 1719-1723, indexed in Pubmed: 16033090 